\title{
Manuela MARTINI, Philippe RYGIEL (dir.), Genre et travail migrant. Mondes atlantiques, $\mathrm{XIX}^{\mathrm{e}}-\mathrm{XX}^{\mathrm{e}}$ siècles
} Numéro spécial des Actes de l'histoire de l'immigration, vol. 9, 2009, Paris, Publibook, 198 p.

\section{Linda Guerry}

\section{OpenEdition}

\section{Journals}

Édition électronique

URL : http://journals.openedition.org/clio/10948

DOI : $10.4000 /$ clio. 10948

ISSN : 1777-5299

Éditeur

Belin

Édition imprimée

Date de publication : 31 décembre 2012

ISSN : 1252-7017

\section{Référence électronique}

Linda Guerry, "Manuela martinı, Philippe RYgiel (dir.), Genre et travail migrant. Mondes atlantiques, $\mathrm{xIx}^{\mathrm{e}}-\mathrm{xx} \mathrm{e}^{\mathrm{e}}$ siècles », Clio. Femmes, Genre, Histoire [En ligne], 36 | 2012, mis en ligne le 13 avril 2018, consulté le 22 septembre 2020. URL : http://journals.openedition.org/clio/10948; DOI : https://doi.org/10.4000/clio. 10948

Ce document a été généré automatiquement le 22 septembre 2020.

Tous droits réservés 


\section{Manuela MARTINI, Philippe RYGIEL (dir.), Genre et travail migrant. Mondes atlantiques, $\mathrm{XIX}^{\mathrm{e}}-\mathrm{XX}^{\mathrm{e}}$ siècles}

Numéro spécial des Actes de l'histoire de l'immigration, vol. 9, 2009, Paris, Publibook, 198 p.

\section{Linda Guerry}

\section{RÉFÉRENCE}

Manuela MARTINI, Philippe RYGIEL (dir.), Genre et travail migrant. Mondes atlantiques, XIX ${ }^{e}$ XXe siècles, numéro spécial des Actes de l'histoire de l'immigration, vol. 9, 2009, Paris, Publibook, $198 \mathrm{p}$.

1 Cet ouvrage fait partie de la série de publications issues du séminaire d'histoire sociale de l'ENS sur le thème des femmes et du genre dans les migrations (2002-2004) et du colloque Histoire Genre Migration tenu à Paris en mars 2006. Le "trinôme classique des sciences sociales » (p.16) genre/migrations/marché du travail est ici abordé d'un point de vue historique à travers des études de cas principalement en Europe et en Amérique du Nord aux $\mathrm{XIX}^{\mathrm{e}}$ et $\mathrm{Xx}^{\mathrm{e}}$ siècles. Faisant le constat d'une "raréfaction relative » (p. 17) des études historiques françaises croisant genre et travail migrant par rapport aux nombreuses recherches sur ce thème en sociologie et en anthropologie et aux travaux des historiens anglo-américains, Manuela Martini et Philippe Rygiel font, dans une longue introduction, un point historiographique sur cette question. En présentant des travaux récents (pour la plupart de chercheurs étrangers) à un public français, ils souhaitent esquisser quelques pistes de réflexion. Dans une première partie sur les migrations de domestiques, le texte présenté par Leslie Page Moch analyse le cas de la migration des Bretons arrivant dans la région parisienne sous la Troisième République. L'auteure met en évidence le poids des représentations combiné à celui des origines et de l'éducation dans la mobilité et les réseaux qui structurent les migrations d'hommes 
et de femmes. Comparant les pratiques matrimoniales des migrants et des migrantes, elle démontre une agency des femmes bien éloignée des stéréotypes. Dans une mise en perspective sur la longue durée (XVII $-\mathrm{XX}^{\mathrm{e}}$ siècle), Raffaella Sarti s'intéresse quant à elle aux continuités/discontinuités du processus d'internationalisation du travail domestique. Jusqu'au milieu du xIx ${ }^{\mathrm{e}}$ siècle, les migrations de domestiques qui se féminisent vont majoritairement des pays riches vers les pays pauvres dans le cadre des politiques coloniales et impérialistes. Puis, après un long déclin de la profession, on assiste à un renversement de tendance: depuis quelques décennies, le nombre de domestiques (fréquemment mariées et mères) augmente et celles-ci connaissent plus souvent qu'autrefois un déclassement social. Dans la deuxième partie du volume intitulée "Métiers de migrantes", Florence Mae Waldron étudie les migrations de Québécois vers la Nouvelle Angleterre du milieu du XIx ${ }^{e}$ au milieu du $x^{e}$ siècle en analysant l'impact des normes de genre sur les processus et les expériences migratoires. Il ressort de l'analyse que l'identité des hommes est fortement liée à l'allégeance nationale (envers le Québec mais aussi envers leur nouvelle patrie) tandis que l'expérience des femmes s'inscrit davantage dans leur nouveau mode de vie où elles saisissent les opportunités offertes par la vie américaine qu'elles ne trouvaient pas dans leur région d'origine.

2 L'article de Karen C. Flynn qui porte sur les migrations d'infirmières caribéennes au Canada après la Seconde Guerre mondiale (certaines sont passées par l'Angleterre) montre des femmes actrices de leur parcours. Malgré une insertion difficile sur le marché du travail canadien dans un secteur en voie de déqualification et de prolétarisation, ces migrantes, dont l'identité personnelle est fortement façonnée par leur profession, se sont adaptées par divers biais à ce nouvel environnement jusqu'à jouer pour certaines des rôles clés, par exemple de direction, dans le secteur des soins au Canada. Étudié par Carine Pina-Guerassimoff, le cas des immigrantes chinoises en France au cours des années 2000, met en évidence l'importance des «institutions migratoires " dans les flux migratoires et l'insertion sur le marché du travail mais souligne également, comme pour celles qui ne sont pas issues de régions traditionnelles d'émigration, la précarité des emplois, les faibles rémunérations et les conditions de travail très difficiles dans le contexte d'une économie ethnique qui recrute de moins en moins de main-d'œuvre. La dernière partie qui a pour titre "Survivre et reproduire " regroupe trois articles. Le texte d'Yves Frenette qui porte sur la correspondance entre une mère (au New Hampshire) et sa fille (qui séjourne dans un couvent au Québec) d'origine canadienne-française entre 1912 et 1915, démontre l'intérêt des sources épistolaires pour les historiens des migrations et de l'ethnicité. L'article de Robert J. Grace sur les migrations saisonnières vers les États-Unis d'Irlandais installés au Québec au XIXe siècle analyse ces mouvements migratoires et surtout leurs conséquences sur l'économie domestique des familles restées au Québec pendant les saisons d'hiver, en particulier les stratégies de survie mises en œuvre par les femmes. Dans le dernier article, Yukari Takai, à travers le cas du travail non-rémunéré des CanadiennesFrançaises installées à Lowell (Massachussetts, États-Unis) au $\mathrm{xx}^{\mathrm{e}}$ siècle, rappelle la persistance de la division genrée du travail domestique et le rôle central des femmes (mères et filles) dans le contexte migratoire. L'auteure montre également que cette configuration traditionnelle ne doit pas masquer les pratiques inédites de ces femmes installées dans un nouvel environnement. Les pistes de recherche explorées dans le volume suscitent l'intérêt d'une lecture genrée des processus et expériences migratoires. Seul regret, les analyses manquent parfois d'une réelle comparaison entre 
les parcours féminins et masculins mais cela n'enlève rien à la qualité des textes présentés.

\section{AUTEURS}

\section{LINDA GUERRY}

Université du Québec à MontréalManuela Martini, Philippe Rygiel (dir.), Genre et travail migrant. Mondes atlantiques, $\mathrm{XIX}^{e}-\mathrm{XX}^{e}$ siècles 